\title{
The Variations of Thermal Contact Resistance and Heat Transfer Rate of the AlN Film Compositing with PCM
}

\author{
Huann-Ming Chou, Jin-Chi Wang, and Yuh-Ping Chang \\ Department of Mechanical Engineering, Kun Shan University, Tainan 710, Taiwan \\ Correspondence should be addressed to Jin-Chi Wang; markfish@mail.ksu.edu.tw
}

Received 1 October 2014; Accepted 11 December 2014

Academic Editor: Mo Li

Copyright ( 2015 Huann-Ming Chou et al. This is an open access article distributed under the Creative Commons Attribution License, which permits unrestricted use, distribution, and reproduction in any medium, provided the original work is properly cited.

\begin{abstract}
The electrical industries have been fast developing over the past decades. Moreover, the trend of microelements and packed division multiplex is obviously for the electrical industry. Hence, the high heat dissipative and the electrical insulating device have been popular and necessary. The thermal conduct coefficient of aluminum nitride (i.e., AlN) is many times larger than the other materials. Moreover, the green technology of composite with phase change materials (i.e., PCMs) is worked as a constant temperature cooler. Therefore, PCMs have been used frequently for saving energy and the green environment. Based on the above statements, it does show great potential in heat dissipative for the AlN film compositing with PCM. Therefore, this paper is focused on the research of thermal contact resistance and heat transfer between the AlN/PCM pairs. According to the experimental results, the heat transfer decreases and the thermal contact resistance increases under the melting process of PCM. However, the suitable parameters such as contact pressures can be used to improve the above defects.
\end{abstract}

\section{Introduction}

The trend of microelements and packed division multiplex is obviously attractive for the research and development department in the electrical industry. To realize the above objects, the high heat dissipative and the electrical insulating device have been popular and necessary.

It is well known that AlN remain stable under the high temperature conditions. Moreover, the thermal conduct coefficient of aluminum nitride is several times larger than the other related materials [1-3]. As a result, it is used popularly for the heat dissipation in the electrical industry. In addition to the above functions, AlN film also has fine electrical insulating properties to avoid the risk of a short circuit of electronic equipment [4-7]. These advantages are always attractive for the research and development department of the electrical corporations [8].

Furthermore, phase change materials (i.e., PCMs) are known as very special materials since they can absorb and store the heat energy as they change their phases, for example, from solid to liquid, and then release that heat energy when they change back to their phase, for example, from liquid to solid. This special property makes the materials very useful in thermal storage applications in general and very valuable in the heat dissipation systems $[9,10]$. The green technology of composite with PCMs is worked as a constant temperature cooler. Therefore, PCMs have been used frequently for the saving energy and the green environment. Based on the above statements, it does show great potential in heat dissipative for the AlN film compositing with PCMs.

Moreover, using continuous responses of triboelectrification and friction coefficient to monitor the dynamic frictional behaviors between the metal materials has been developed successfully by the authors [11]. The experimental results have shown that the thermal contact resistance is obviously determined by the real contact areas between the interfaces of the metal pairs [12]. The most important parameters for the real contact areas are normal loads and surface hardness of the materials. However, the defects of material crystals always significantly influence the heat transfer of AlN [1-7]. Therefore, it is necessary to clarify the relationships between the structure of AlN/PCM and the efficiency of heat transfer. Based on the above expressions, this paper is focused on the research of heat conduction and thermal contact resistance 


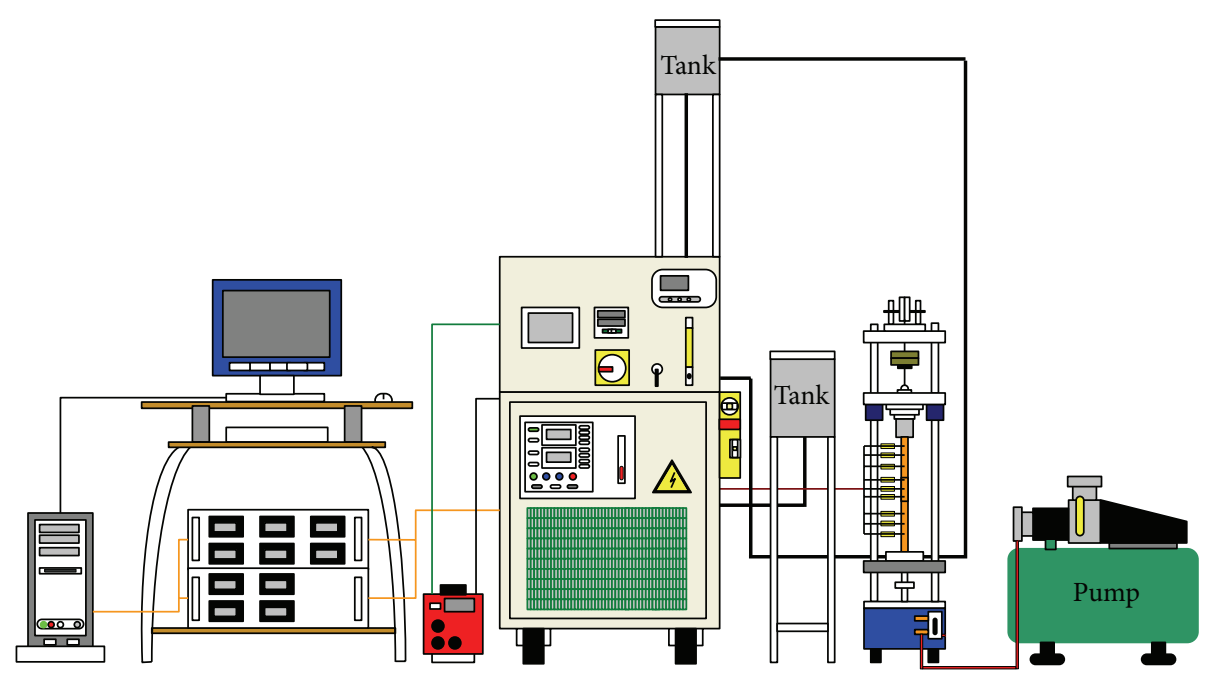

FIGURE 1: The schematic diagram of the thermal contact resistance tester with the measuring systems.

between the pair of AlN/PCM and the copper material by referring the results of thermal contact resistance between the interfaces in the previous paper [12].

\section{Experimental Equipment and Procedures}

2.1. Experimental Equipment. The schematic diagram of the thermal contact resistance tester with the measuring systems is shown in Figure 1. The voltage signals from the measurement points of the ten thermocouples were transferred to a temperature extractor. As a result, the temperatures at each measuring point can be obtained by the calculations and the calibrations. Based on the above results, the thermal contact resistance and the heat transfer rate can therefore be analyzed by the following three mathematical formulas as shown in Section 2.3.

The main parts of the experimental apparatus have been shown in Figure 2. The loading system contains the following elements: one-way pneumatic valve by manual control, with a pneumatic cylinder. The gas comes from a 1HP air compressor. Copper is used as the main heat transfer channel: The heat transfer stick $(\Phi 20 \mathrm{~mm} \times 110 \mathrm{~mm}$, drilling $\Phi 1.4 \mathrm{~mm} \times$ deep $10 \mathrm{~mm}) \times 2$; Copper substrate $(\Phi 20 \mathrm{~mm} \times 20 \mathrm{~mm}$, drilling $\Phi$ $1.4 \mathrm{~mm} \times 10 \mathrm{~mm}$ depth) $\times 1$.

The ceramic glass fibers are used as an insulator $(k=$ $\left.0.036 \mathrm{~W} / \mathrm{m}^{\circ} \mathrm{C}\right)$. Moreover, the heating apparatus included the three heating poles. The fitting counterweights $(1 \mathrm{kgw} \times$ $3,5 \mathrm{kgw} \times 2$, and $10 \mathrm{kgw} \times 1$ ) were used to maintain the equilibrium of the contact pressure. Besides, an ice water maker and a water circulating pump were disposed as the temperature regulator.

2.2. Test Specimens. The experimental specimens were made of AlN thin flakes compositing with PCM. Physical properties of the test specimens are shown in Table 1. The thickness of AlN is about $0.7 \mathrm{~mm}$. The melting point of the PCM is $80^{\circ} \mathrm{C}$ under the standard atmosphere. The design of the test specimens is shown in Figure 3(a). AlN thin flakes, PCM,
TABLE 1: Physical properties of AlN and Cu.

\begin{tabular}{lcc}
\hline & AlN & $\mathrm{Cu}$ \\
\hline Melting point $\left({ }^{\circ} \mathrm{C}\right)$ & 2200 & 1082 \\
Thermal conductivity $\left(\mathrm{W} / \mathrm{m}^{\circ} \mathrm{C}\right)$ & $140-180$ & 398 \\
\hline
\end{tabular}

copper substrate, and the heat transfer stick are shown in Figures 3(b) and 3(c).

2.3. Experimental Procedures. Two kinds of thermal contact resistance are investigated in this study. The data from the upper measuring point is $R_{1}$ and that from the lower point is $R_{2}$. There are several factors for $R_{1}$ and $R_{2}$, such as pressure, temperature, hardness, and surface roughness. Therefore, it is necessary to analyze and calculate the experimental parameters step by step.

The formula of the heat transfer $(k)$ :

$$
q=-k A \frac{d T}{d x}=\frac{T_{a}-T_{b}}{R_{c}} .
$$

The formula of the thermal contact resistance $(R)$ :

$$
R_{1}=\frac{T_{a 1}-T_{a 2}}{q}, \quad R_{2}=\frac{T_{b 1}-T_{b 2}}{q} .
$$

Moreover, the related temperatures are obtained by the following:

$$
\frac{T_{1}-T_{2}}{X_{1}-X_{2}}=\frac{T_{3}-T_{4}}{X_{3}-X_{4}}
$$

In this study, the heating temperatures were set as $40^{\circ} \mathrm{C}$, $50^{\circ} \mathrm{C}, 60^{\circ} \mathrm{C}$, and $70^{\circ} \mathrm{C}$. Moreover, the temperature of the cold water circulating system was fixed as $10^{\circ} \mathrm{C}$. Before each experiment, the warming time for the experimental equipment was set as 4 hours. Normal loads were set as $0.5 \mathrm{kgw}$ and $1.5 \mathrm{kgw}$; that is, the corresponding pressures 


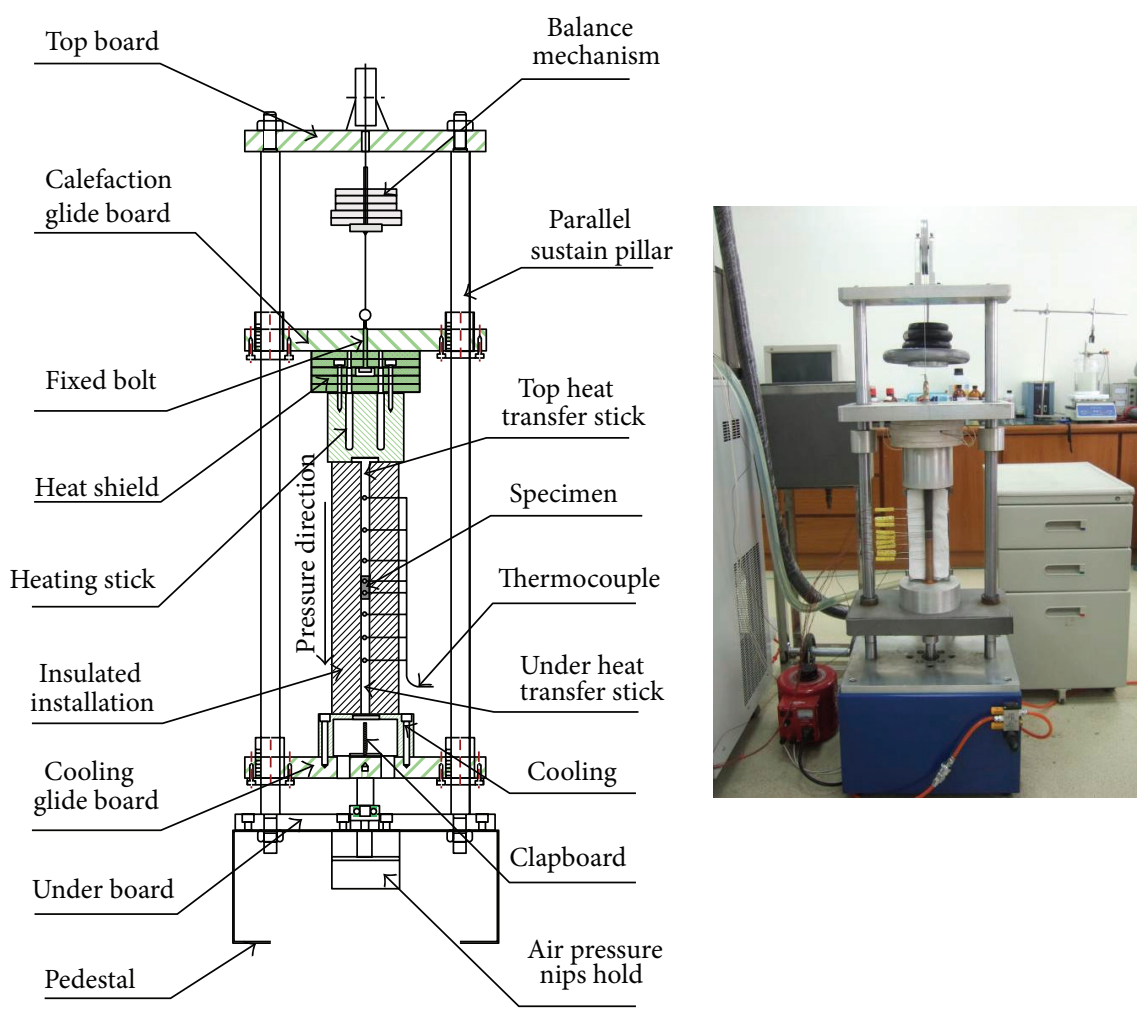

FIgURE 2: The main parts of the experimental apparatus.

were $16 \mathrm{kPa}$ and $48 \mathrm{kPa}$. The average temperature during the experimental period was $25 \pm 3^{\circ} \mathrm{C}$, and the average relative humidity was about $65 \%$.

\section{Results and Discussions}

3.1. Experimental Results under Lower Contact Pressure. Figure 4 shows the effects of heating temperatures on thermal contact resistances for $\mathrm{Cu} / \mathrm{PCM}-\mathrm{AlN} / \mathrm{Cu}$ under $16 \mathrm{kPa}$ $(0.5 \mathrm{kgw})$. It is seen from this figure that the thermal contact resistance $\left(R_{1}\right)$ increases from 1.4 to $1.9^{\circ} \mathrm{C} / \mathrm{W}$ with the heating temperature increasing from 40 to $50^{\circ} \mathrm{C}$. Furthermore, the thermal contact resistance further increases to about 3 $3.5^{\circ} \mathrm{C} / \mathrm{W}$ when the heating temperature is in the range of $60 \sim 70^{\circ} \mathrm{C}$. Similar tendency can be found for the thermal contact resistance $\left(R_{2}\right)$. The above results can be reasonably explained by the fact that the melting point of the PCM should decrease with increasing the contact pressure. Beyond the experimental time of $3600 \mathrm{~s}$, the PCM had melted in the interface under a constant contact pressure when the heating temperature reaches $70^{\circ} \mathrm{C}$. Therefore, not only heat transfer but also heat convection occurs between the interfaces. As a result, the thermal contact resistance shows complex variations in the range of $60 \sim 70^{\circ} \mathrm{C}$.

The effects of heating temperatures on heat transfer rates for $\mathrm{Cu} / \mathrm{PCM}-\mathrm{AlN} / \mathrm{Cu}$ under $16 \mathrm{kPa}(0.5 \mathrm{kgw})$ are shown in Figure 5. This figure shows that the heat transfer rate is about $9 \sim 10 \mathrm{~W}$ when the heating temperature is in the range of $40 \sim$ $50^{\circ} \mathrm{C}$. However, the heat transfer rate significantly increases from 7 to $11 \mathrm{~W}$ with the heating temperature increasing from 60 to $70^{\circ} \mathrm{C}$.

Furthermore, it is seen from Figure 6 that the thermal contact resistance of $\mathrm{Cu} / \mathrm{PCM}-\mathrm{AlN} / \mathrm{Cu}$ is about $3.5^{\circ} \mathrm{C} / \mathrm{W}$ under steady state. However, it shows only $2^{\circ} \mathrm{C} / \mathrm{W}$ under steady state for $\mathrm{Cu} / \mathrm{PCM} / \mathrm{Cu}$ in Figure 7. Moreover, the temperature difference between $T_{a 1}$ and $T_{a 2}$ is about $20^{\circ} \mathrm{C}$.

From the above experimental results, it is apparent that the AlN film between $\mathrm{Cu} / \mathrm{PCM}$ and $\mathrm{AlN} / \mathrm{Cu}$ increases the thermal contact resistance and decreases the heat transfer rate when the heating temperature is smaller than $70^{\circ} \mathrm{C}$. However, the thermal contact resistance is shown to be smaller and stable when the heating temperature reaches $70^{\circ} \mathrm{C}$. Moreover, the corresponding heat transfer rate also is shown to be larger. These can be reasonably explained by the fact that PCMs fuse at a higher temperature. Therefore, the air holes are filled by the softened PCM. In order to verify the above phenomenon under higher pressure, the experimental results under $48 \mathrm{kPa}$ were measured.

3.2. Experimental Results under Higher Contact Pressure. Figure 8 shows the effects of heating temperatures on thermal contact resistances for $\mathrm{Cu} / \mathrm{PCM}-\mathrm{AlN} / \mathrm{Cu}$ under $48 \mathrm{kPa}$ $(1.5 \mathrm{kgw})$. It is seen from this figure that the thermal contact resistance $\left(R_{1}\right)$ increases from 1.4 to $1.7^{\circ} \mathrm{C} / \mathrm{W}$ with the heating temperature increasing from 40 to $50^{\circ} \mathrm{C}$. Moreover, the thermal contact resistance further increases to about 2.1 $2.9^{\circ} \mathrm{C} / \mathrm{W}$ when the heating temperature is in the range of $60 \sim 70^{\circ} \mathrm{C}$. Similar tendency can be also found for the thermal 


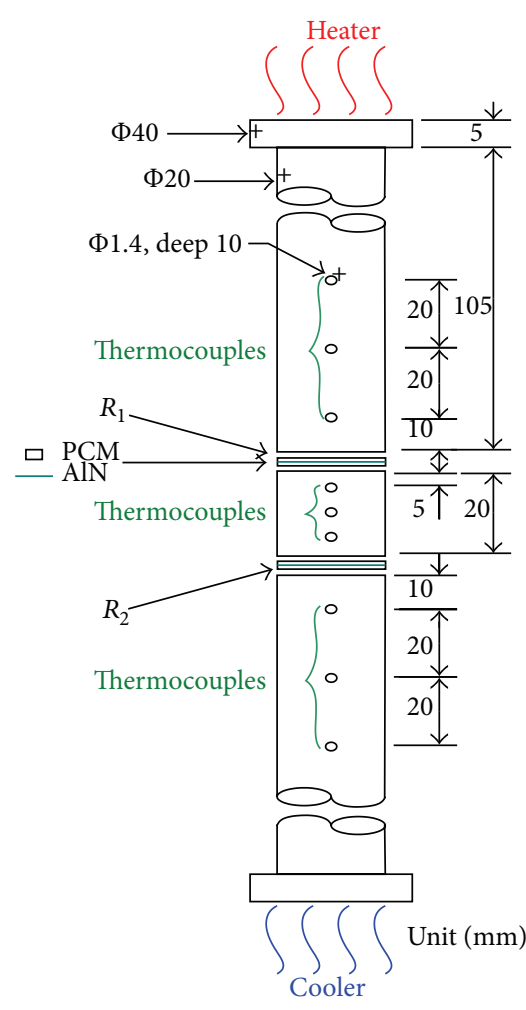

(a)

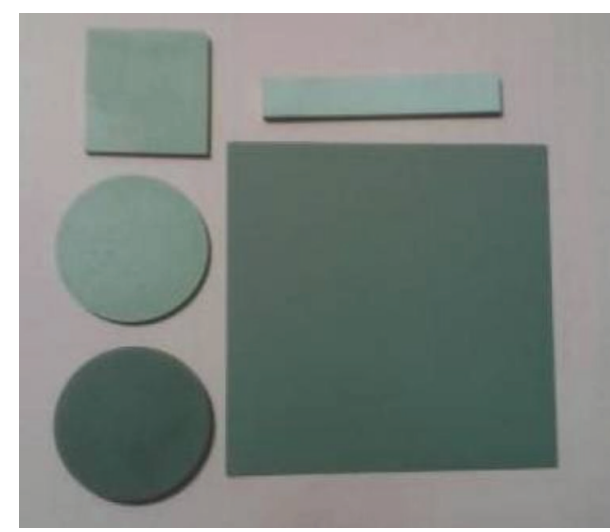

(b)

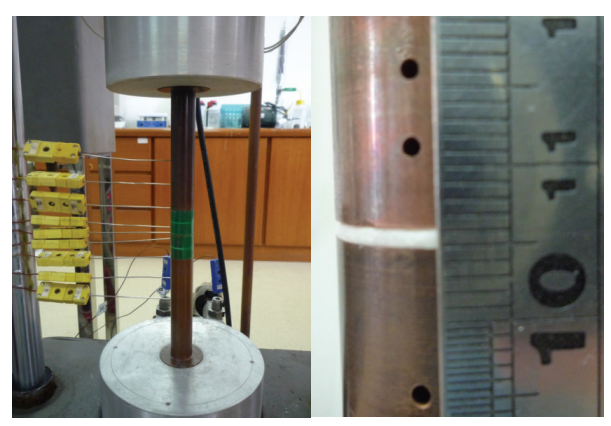

(c)

Figure 3: (a) The size and shape of the specimens, (b) AlN flake, and (c) AlN film compositing with PCM.

contact resistance $\left(R_{2}\right)$. The effects of heating temperatures on heat transfer rates for Cu/PCM-AlN/Cu under $48 \mathrm{kPa}$ $(1.5 \mathrm{kgw})$ are shown in Figure 9. This figure shows that the heat transfer rate is about $8 \sim 9.5 \mathrm{~W}$ when the heating temperature is in the range of $40 \sim 50^{\circ} \mathrm{C}$. However, the heat transfer rate significantly increases from 10.5 to $12 \mathrm{~W}$ with the heating temperature increasing from 60 to $70^{\circ} \mathrm{C}$.

Compared to the above results under $16 \mathrm{kPa}$, the variations of thermal contact resistance and heat transfer rate are similar. Moreover, the real contact areas significantly increase with increasing the contact pressure. Therefore, the thermal contact resistance decreases and the heat transfer rate increases under the higher contact pressure.

Furthermore, it is seen from Figure 10 that the thermal contact resistance of $\mathrm{Cu} / \mathrm{PCM}-\mathrm{AlN} / \mathrm{Cu}$ is about $2.5^{\circ} \mathrm{C} / \mathrm{W}$ under steady state. However, it shows only $2^{\circ} \mathrm{C} / \mathrm{W}$ under steady state for $\mathrm{Cu} / \mathrm{PCM} / \mathrm{Cu}$ in Figure 11. Moreover, the temperature difference between $T_{a 1}$ and $T_{a 2}$ is about $20^{\circ} \mathrm{C}$.

Compared to the two cases of $\mathrm{Cu} / \mathrm{PCM}-\mathrm{AlN} / \mathrm{Cu}$ and $\mathrm{Cu} / \mathrm{PCM} / \mathrm{Cu}$, the thermal contact resistance increases and the heat transfer rate decreases under the higher temperature. However, the thermal contact resistance decreases and the heat transfer rate increases due to the fact that the air holes are filled by the softened PCM under the higher contact pressure. This indicates that the PCM had fused at this temperature and pressure. Not only heat transfer but also heat convection occurred between the interfaces.

\section{Conclusions}

The thermal contact resistance and the heat transfer rate of $\mathrm{Cu} / \mathrm{PCM}-\mathrm{AlN} / \mathrm{Cu}$ and $\mathrm{Cu} / \mathrm{PCM} / \mathrm{Cu}$ were experimentally 


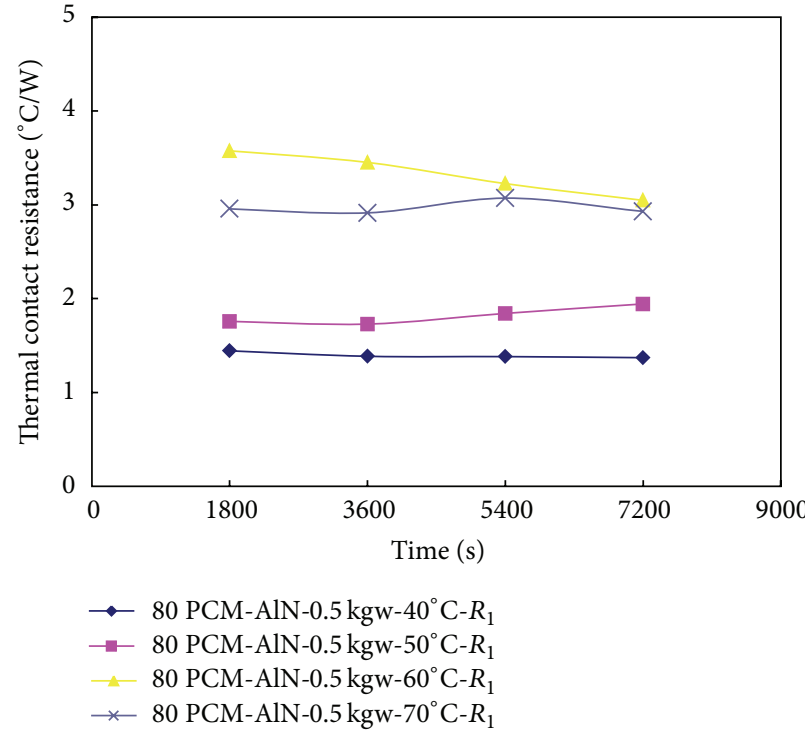

(a) $R_{1}$ thermal contact resistance

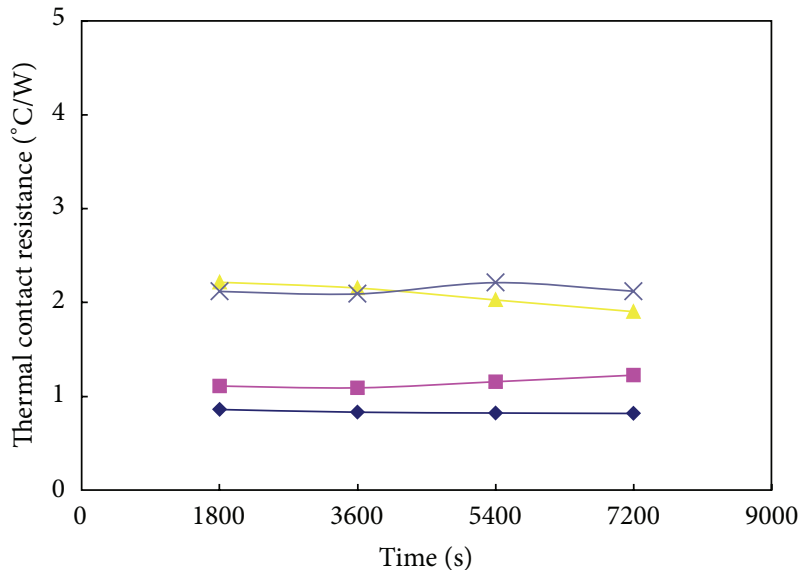

$\rightarrow-80$ PCM-AlN- $0.5 \mathrm{kgw}-40^{\circ} \mathrm{C}-R_{2}$
$\rightarrow-80$ PCM-AlN- $0.5 \mathrm{kgw}-50^{\circ} \mathrm{C}-R_{2}$
$\rightarrow 80$ PCM-AlN-0.5 kgw- $60^{\circ} \mathrm{C}-R_{2}$
$\star \quad 80$ PCM-AlN- $0.5 \mathrm{kgw}-70^{\circ} \mathrm{C}-R_{2}$

(b) $R_{2}$ thermal contact resistance

Figure 4: Effects of heating temperatures on thermal contact resistances for Cu/PCM-AlN/Cu under $16 \mathrm{kPa}$ (normal load of $0.5 \mathrm{kgw}$ ). (a) $R_{1}$ and (b) $R_{2}$.

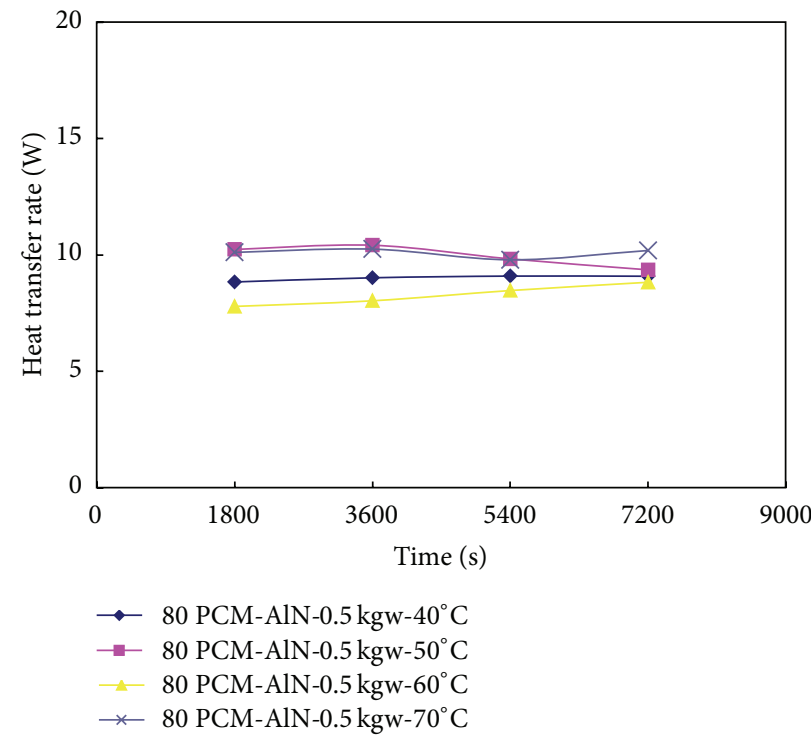

FIGURE 5: Effects of heating temperatures on heat transfer rates for $\mathrm{Cu} / \mathrm{PCM}-\mathrm{AlN} / \mathrm{Cu}$ under $16 \mathrm{kPa}$ (normal load of $0.5 \mathrm{kgw}$ ).

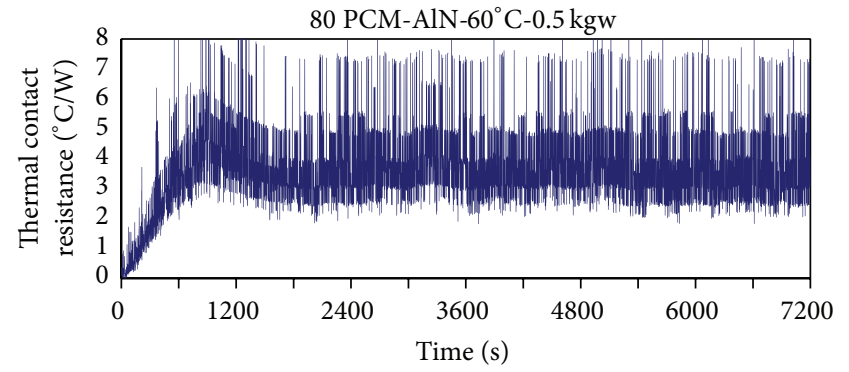

(a)

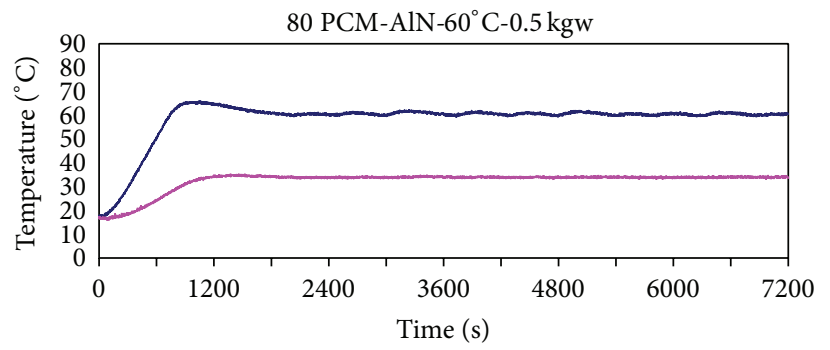

(b)

FIGURE 6: Variations of thermal contact resistance and temperature for $\mathrm{Cu} / \mathrm{PCM}-\mathrm{AlN} / \mathrm{Cu}$ under $16 \mathrm{kPa}$ (normal load of $0.5 \mathrm{kgw}$ ). 


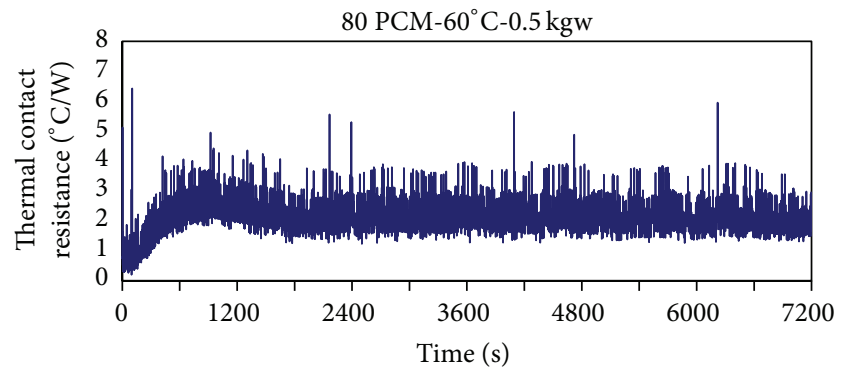

(a)

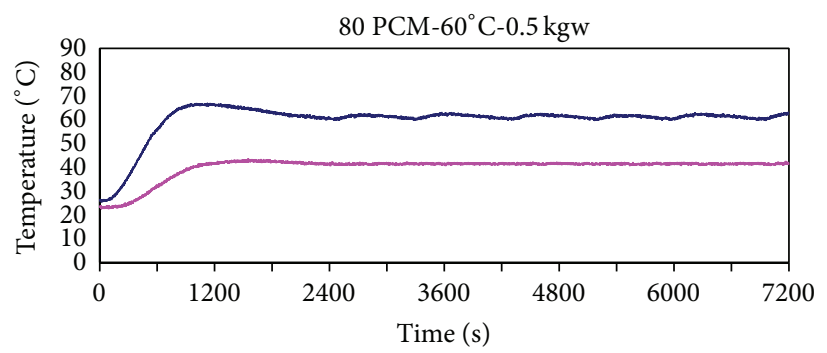

(b)

FIgURE 7: Variations of thermal contact resistance and temperature for $\mathrm{Cu} / \mathrm{PCM} / \mathrm{Cu}$ under $16 \mathrm{kPa}$ (normal load of $0.5 \mathrm{kgw}$ ).
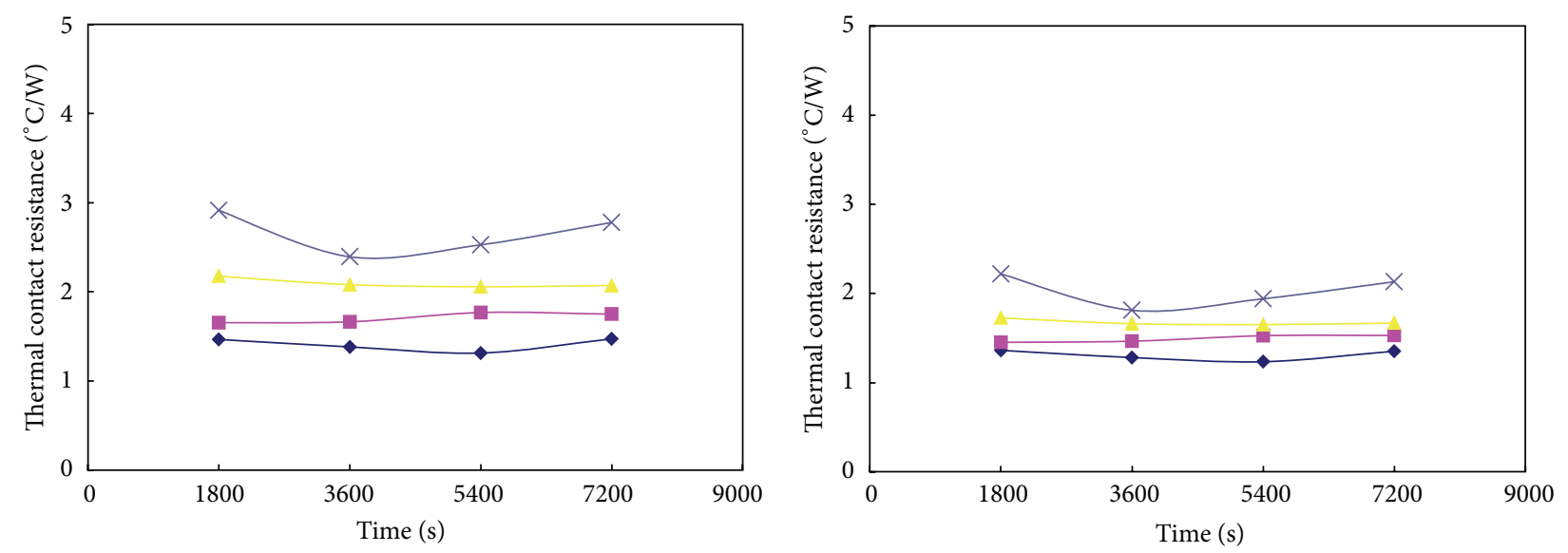

-80 PCM-AlN- $1.5 \mathrm{kgw}-40^{\circ} \mathrm{C}-R_{1}$
-80 PCM-AlN-1.5 kgw- $50^{\circ} \mathrm{C}-R_{1}$
-80 PCM-AlN- $1.5 \mathrm{kgw}-60^{\circ} \mathrm{C}-R_{1}$
$* 80$ PCM-AlN- $1.5 \mathrm{kgw}-70^{\circ} \mathrm{C}-R_{1}$

(a) $R_{1}$ thermal contact resistance

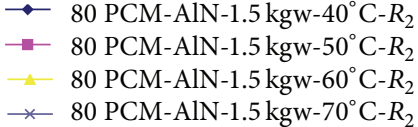

(b) $R_{2}$ thermal contact resistance

Figure 8: Effects of heating temperatures on thermal contact resistances for $\mathrm{Cu} / \mathrm{PCM}-\mathrm{AlN} / \mathrm{Cu}$ under $48 \mathrm{kPa}$ (normal load of $1.5 \mathrm{kgw}$ ). (a) $R_{1}$ and (b) $R_{2}$.

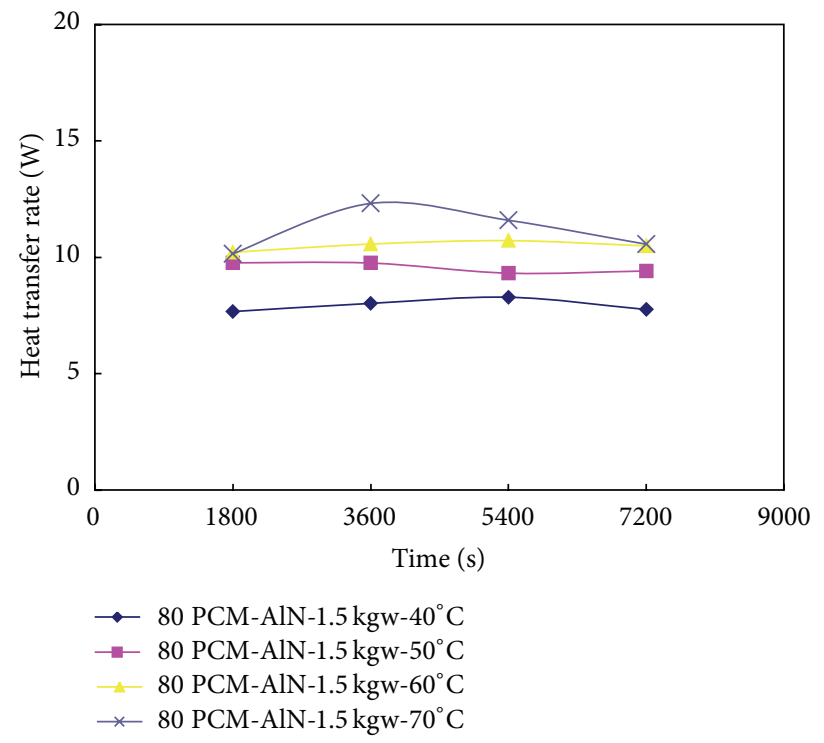

FIGURE 9: Effects of heating temperatures on heat transfer rates for $\mathrm{Cu} / \mathrm{PCM}-\mathrm{AlN} / \mathrm{Cu}$ under $48 \mathrm{kPa}$ (normal load of $1.5 \mathrm{kgw}$ ). 


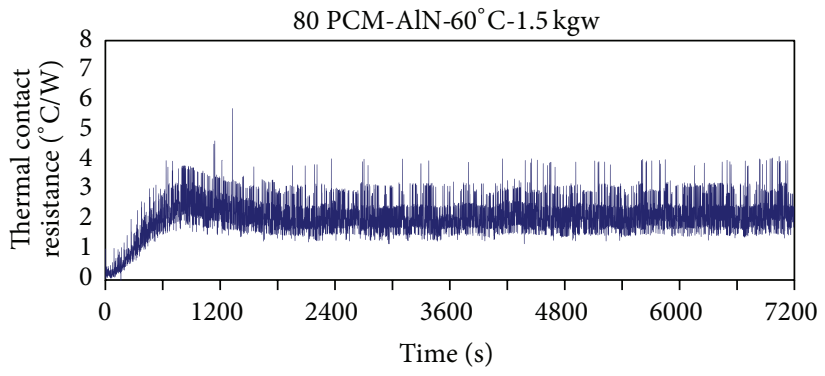

(a)

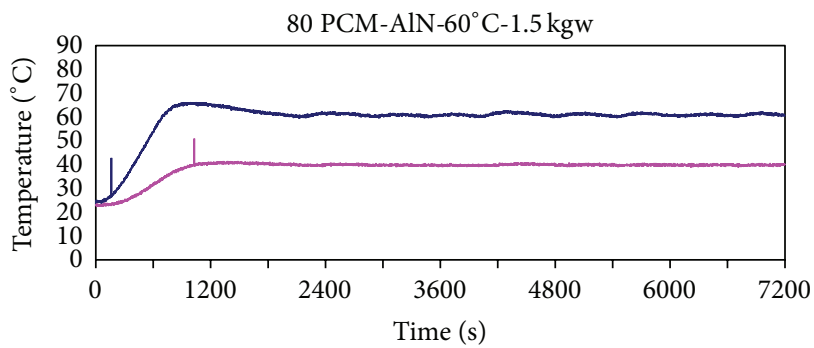

(b)

FIGURE 10: Variations of thermal contact resistance and temperature for $\mathrm{Cu} / \mathrm{PCM}-\mathrm{AlN} / \mathrm{Cu}$ under $48 \mathrm{kPa}$ (normal load of $1.5 \mathrm{kgw}$ ).

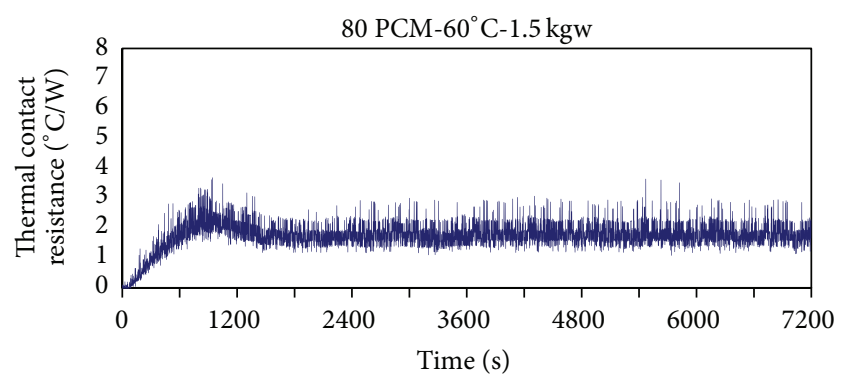

(a)

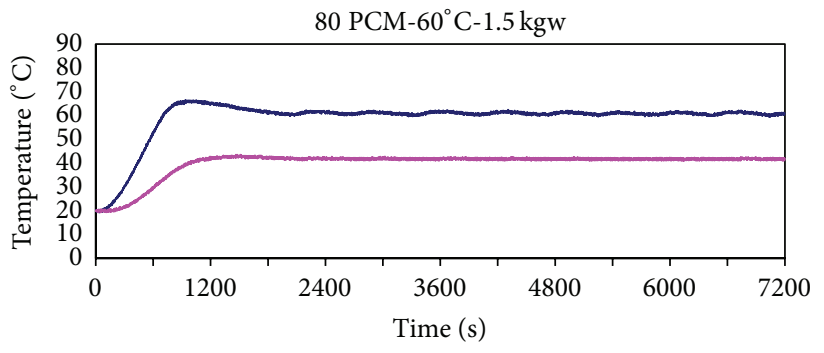

(b)

FIGURE 11: Variations of thermal contact resistance and temperature for $\mathrm{Cu} / \mathrm{PCM} / \mathrm{Cu}$ under $48 \mathrm{kPa}$ (normal load of $1.5 \mathrm{kgw}$ ).

investigated in this study. From the experimental results, the following conclusions were drawn.

(1) The AlN film between Cu/PCM and AlN/Cu increases the thermal contact resistance and decreases the heat transfer rate when the heating temperature is smaller than $70^{\circ} \mathrm{C}$.

(2) The real contact areas significantly increase with increasing the contact pressure under the melting process of PCM. Therefore, the thermal contact resistance decreases and the heat transfer rate increases under the higher contact pressure.

(3) The heat transfer decreases and the thermal contact resistance increases under the melting process of PCM. However, not only heat transfer but also heat convection occurs between the interfaces at $70^{\circ} \mathrm{C}$ and $48 \mathrm{kPa}$. Therefore, the higher contact pressures can be used to improve the above defects.

\section{Conflict of Interests}

The authors declare that there is no conflict of interests regarding the publication of this paper.

\section{Acknowledgment}

The authors would like to express their appreciation to the National Science Council in Taiwan for their financial support under Grant no. NSC 101-2221-E-168-014.

\section{References}

[1] Y. Kurokawa, K. Utsumi, and H. Takamizawa, "Development and microstructural characterization of high-thermalconductivity aluminum nitride ceramics," Journal of the American Ceramic Society, vol. 71, no. 7, pp. 588-594, 1988.

[2] J. H. Edgar and W. J. Meng, Properties of Group III Nitrides, 1993.

[3] M. I. Nieto, R. Martínez, L. Mazerolles, and C. Baudín, "Improvement in the thermal shock resistance of alumina through the addition of submicron-sized aluminium nitride particles," Journal of the European Ceramic Society, vol. 24, no. 8, pp. 2293-2301, 2004.

[4] X. Xu, H. Wu, and Z. Jin, "Studies of the structure and surface roughness of AlN thin films," Rare Metal Materials and Engineering, vol. 29, no. 6, pp. 394-397, 2000.

[5] Y. D. Wang, H. P. Zhou, L. Qiao, H. Chen, and H. B. Jin, "Thermal conductivity of AlN/PE composite substrate," Journal of Inorganic Materials, vol. 15, no. 6, pp. 1030-1036, 2000.

[6] B. Qiao, Z. Liu, and Y. Li, "Effect of technical parameters on deposition rate of AlN films prepared by magnetron reactive sputtering," Journal of Northwestern Polytechnical University, vol. 22, no. 22, pp. 260-263, 2004.

[7] J. Zhang, W. Wang, X.-H. Zeng, Y.-Z. Shi, and H.-Q. Fan, "Fabrication and dielectric property of polymer-matrix composites containing AlN particles for electronic substrates," Journal of Aeronautical Materials, vol. 26, no. 3, pp. 341-342, 2006.

[8] Y. C. Lin, Processing parameters on the performance of aluminum nitride [M.S. thesis], Department of Mechanical Engineering, National Taiwan University of Science and Technology, 2005.

[9] H.-M. Chou, C.-R. Chen, and V.-L. Nguyen, "A new design of metal-sheet cool roof using PCM," Energy and Buildings, vol. 57, pp. 42-50, 2013. 
[10] K. A. R. Ismail and R. I. R. Moraes, "A numerical and experimental investigation of different containers and PCM options for cold storage modular units for domestic applications," International Journal of Heat and Mass Transfer, vol. 52, no. 1920, pp. 4195-4202, 2009.

[11] Y.-P. Chang, "A novel method of using continuous triboelectrification variations for monitoring the tribological properties between pure metal films," Wear, vol. 262, no. 3-4, pp. 411423, 2007.

[12] H. M. Chou, J. C. Wang, and Y. P. Chang, "An experimental study on heat conduction and thermal contact resistance for the AlN flake," Advances in Materials Science and Engineering, vol. 2013, Article ID 352173, 7 pages, 2013. 


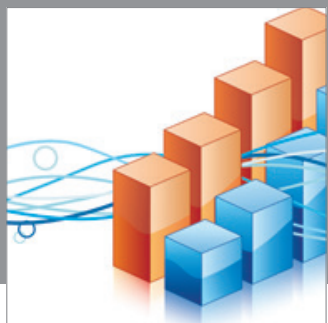

Advances in

Operations Research

mansans

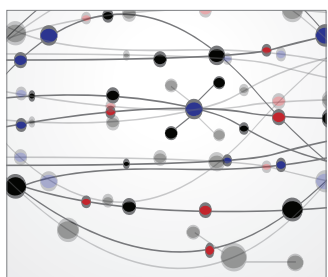

The Scientific World Journal
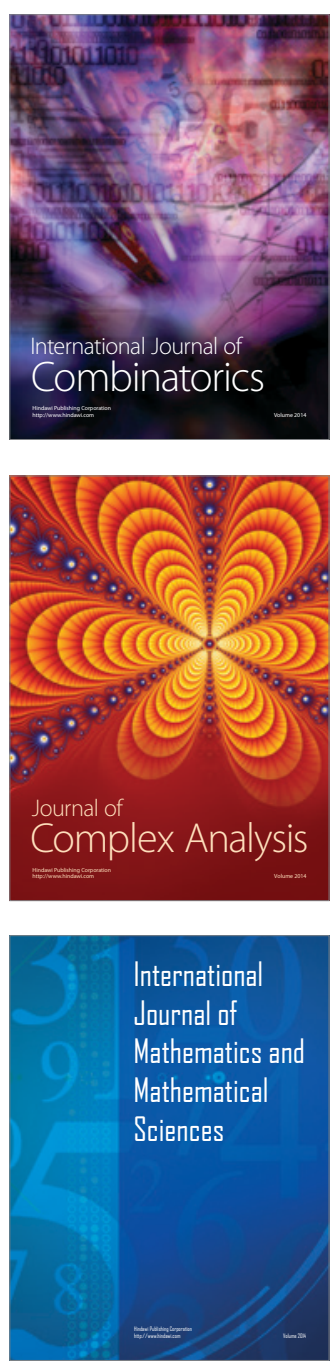
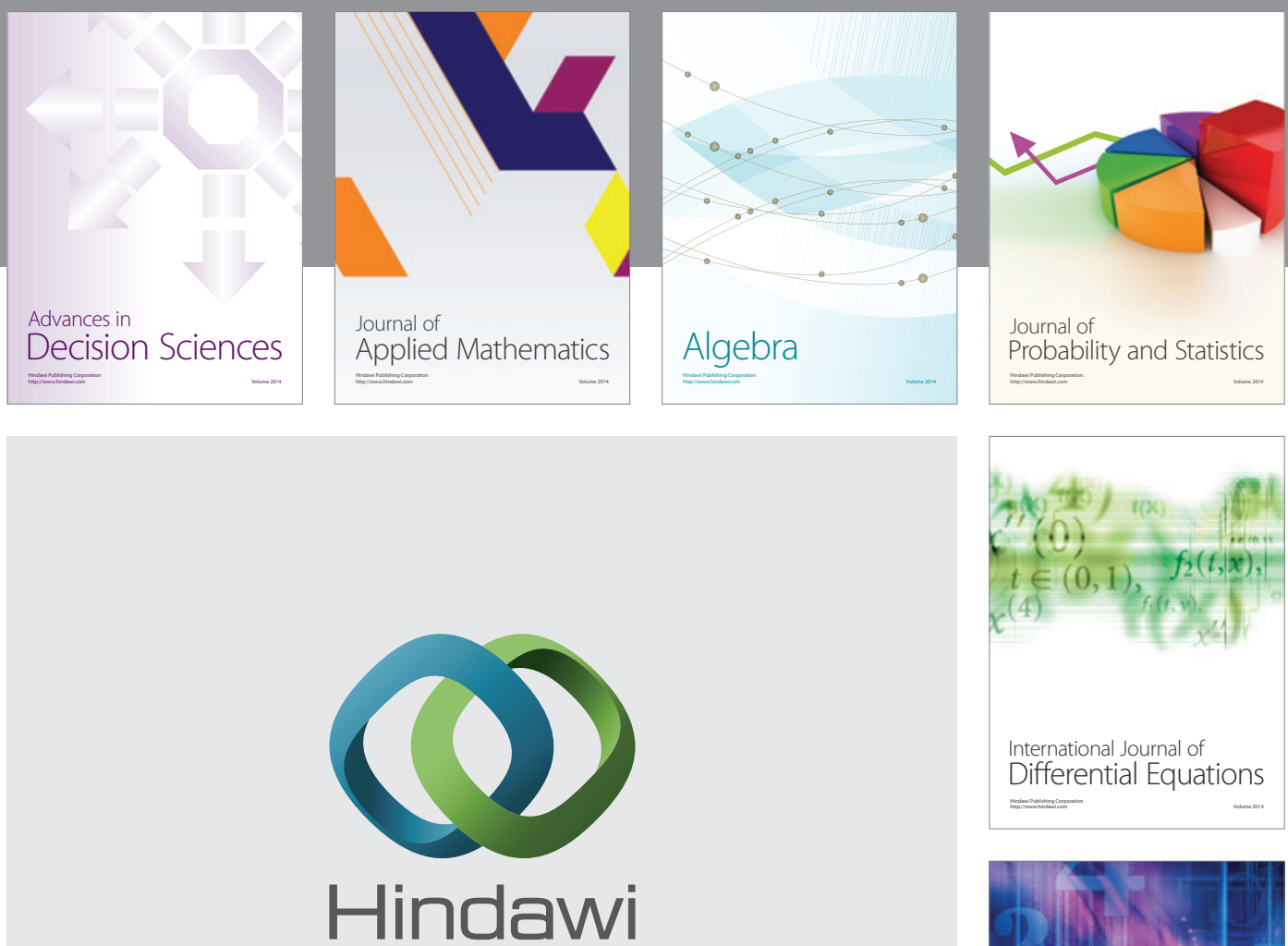

Submit your manuscripts at http://www.hindawi.com
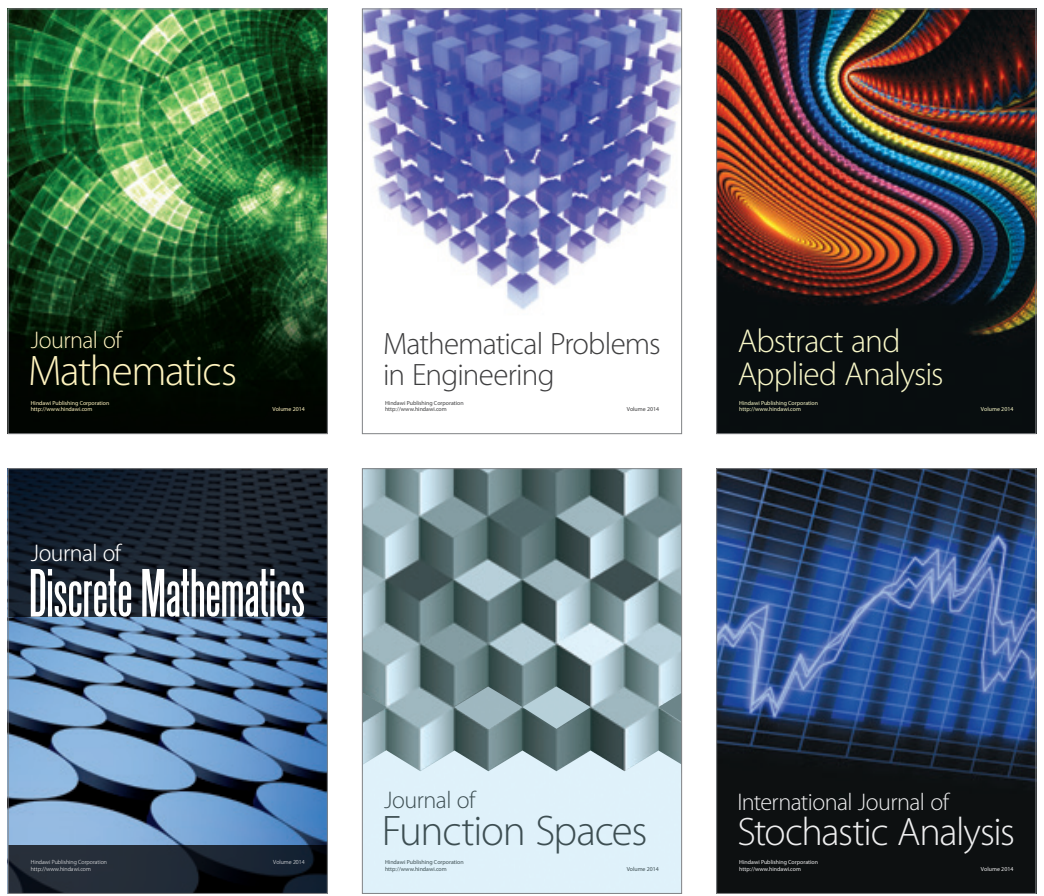

Journal of

Function Spaces

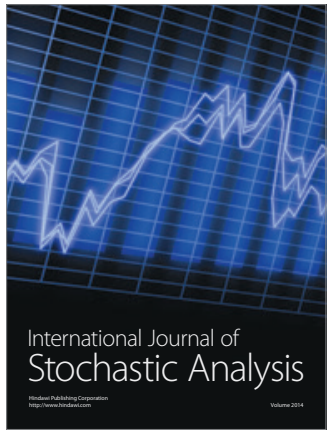

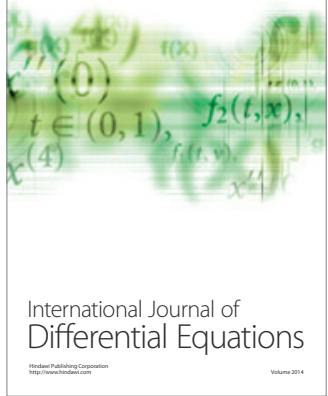
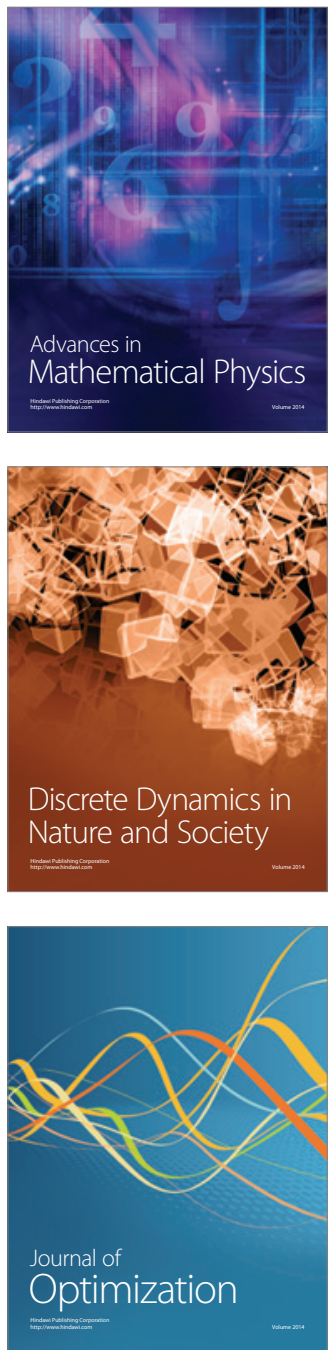